Abstract-Multiple structures can be used for the age determination of fishes. Choosing the structure that provides the most precise ages is important for the provision of consistent data for the management of commercially and recreationally important species, such as the American shad (Alosa sapidissima). In this study, we compared the precision of age estimates obtained from sagittal otoliths, vertebrae, scales, and opercula as structures for the age determination of American shad. Two readers examined structures removed from 462 American shad, which were collected from the Merrimack River in Lawrence, Massachusetts, during May and June of 2008-2010. The precision of age estimates were evaluated by comparisons of ages from different readers and structures. Age estimates determined from otoliths were the most precise $(76.2 \%$ agreement, $2.99 \%$ coefficient of variation). Ages derived from scales were overestimated in young ( $\leq 5$ years) fish and underestimated in older ( $\geq 7$ years) fish, compared with ages determined from otoliths. Age estimates determined from vertebrae agreed with those obtained from otoliths better than ages from any other structure tested, but they were less precise and vertebrae required more processing than otoliths. Opercula were difficult to read, resulting in underestimation of the ages of fish that were age 5 and older. The results of this study indicate that the sagittal otolith is the most appropriate structure for determining the age of American shad.

Manuscript submitted 25 October 2013. Manuscript accepted 25 November 2014. Fish. Bull. 113:47-54 (2015).

doi: $10.7755 /$ FB.113.1.5

The views and opinions expressed or implied in this article are those of the author (or authors) and do not necessarily reflect the position of the National Marine Fisheries Service, NOAA.

\title{
Comparison of 4 aging structures in the American shad (Alosa sapidissima)
}

\author{
Scott P. Elzey (contact author) \\ Katie A. Rogers \\ Kimberly J. Trull \\ Email address for contact author: scott.elzey@state.ma.us \\ Fish Biology Program \\ Massachusetts Division of Marine Fisheries \\ 30 Emerson Avenue \\ Gloucester, Massachusetts 01930
}

The American shad (Alosa sapidissima) is an anadromous fish found from the Gulf of St. Lawrence in Canada to the St. Johns River in Florida (Walburg and Nichols, 1967; Hassleman et al., 2013). It is the largest species of the family Clupeidae found in waters of the United States (Walburg and Nichols, 1967), and individuals commonly reach sizes of $50 \mathrm{~cm}$ in total length (TL) (Scott and Leim, 1966; Scott and Scott, 1988; Collette and Klein-MacPhee, 2002). This species spends most of its life in saltwater but returns to freshwater rivers and streams in the spring to spawn. Most individuals return to spawn for the first time at age 4 or 5 (Walburg and Nichols, 1967; Scott and Leim, 1966; Leggett and Carscadden, 1978; Ross, 1991).

The American shad is a culturally and ecologically important species. This shad is a sought after game fish by recreational anglers, who prize it for its roe. It also composes an important forage base for many species of fishes (Ross, 1991). Populations of American shad have declined because of fishing pressure and dams that have caused a loss of access to their spawning grounds (Ross, 1991; Latour et al., 2012; Raabe and Hightower, 2014). These factors all make management of American shad important.

American shad are commonly aged by Cating's (1953) scale technique, in which counts of transverse grooves are used to identify the most probable locations of annuli. Recent studies have discredited the accuracy of this method (McBride et al., 2005; Duffy et al., 2011, 2012; Upton et al., 2012). Recently, the use of otoliths to age American shad has been evaluated and validated as accurate with fish of known age for ages 3-9 (Duffy et al., 2012). However, Beamish and McFarlane (1983) have recommended validation of an aging technique for all reported ages and an exploration of alternative aging structures.

The choice of aging structure is critical because not all structures are suitable for age determination of a given species. For example, although scales were historically used to age the white sucker (Catostomus commersonii), Beamish and Harvey (1969), after verifying yearly deposition of annuli, found that pectoralfin rays yielded older ages than did scales of individuals older than age 5. Later studies on white suckers found that fin rays yielded biased ages in the oldest individuals and that the otolith was the most appropriate structure (Thompson and Beckman, 1995; Sylvester and Berry, 2006). These examples show the importance of evaluating each structure for age determination. 
For many species, the otolith is the preferred structure. Otoliths were found to be more suitable for aging than were scales for a large number of species, such as lake whitefish (Coregonus clupeaformis [Barnes and Power, 1984]), striped bass (Morone saxatilis [Welch et al., 1993; Secor et al., 1995]), white crappie (Pomoxis annularis [Boxrucker, 1986]), bluefish (Pomatomus saltatrix [Robillard et al., 2009]), bull trout (Salvelinus confluentus [Zymonas and McMahon, 2009]), Dolly Varden (Salvelinus malma [Stolarski and Sutton, 2013]), and summer flounder (Paralichthys dentatus [Sipe and Chittenden, 2001]). Although comparisons between scales and otoliths have been relatively common, more comprehensive studies that involve multiple structures are rarer. Scales, otoliths, vertebrae, opercula, and subopercula were used to age pontic shad (Alosa pontica) in two recent studies that included the family Clupeidae [Yilmaz and Polat, 2002; Višnjić-Jeftić et al., 2009]), yet no such comprehensive study has been completed for the American shad.

The Interstate Fishery Management Plan for Shad and River Herring requires that biological data, including ages, be collected for American shad annually by states from Maine to Florida (ASMFC ${ }^{1}$ ). These data are used to make informed decisions regarding the management of this species $\left(\mathrm{ASMFC}^{2}\right)$. Specifically, age data are used to estimate mortality, determine the age of recruitment into spawning populations, and characterize the age structure of populations by sex. Current data used for these purposes are based on scales, which have been shown to produce unreliable ages (McBride et al., 2005; Duffy et al., 2011, 2012; Upton et al., 2012). Given the importance of age data for the assessment and management of American shad, it is imperative that an unbiased and precise aging method be used. The objective of this study was to compare the precision of age estimates obtained from the scales, otoliths, opercula, and vertebrae of American shad.

\section{Materials and methods}

American shad were collected by dip net from the fish lift at the Essex dam in Lawrence, Massachusetts, on the Merrimack River during May and June of 20082010. American shad were distinguished from other species by morphological characteristics described by Collette and Klein-MacPhee (2002). Samples were fro-

\footnotetext{
${ }^{1}$ ASMFC (Atlantic States Marine Fisheries Commission). 1999. Amendment 1 to the Interstate Fishery Management Plan for Shad \& River Herring. Fishery Management Report No. 35 of the Atlantic States Marine Fisheries Commission, 77 p. [Available from http://www.asmfc.org/uploads/file/shadam1.pdf.]

2 ASMFC (Atlantic States Marine Fisheries Commission). 2012. River Herring Benchmark Stock Assessment, vol. 1. Stock Assessment Report No. 12-02 of the Atlantic States Marine Fisheries Commission, 392 p. [Available from http:// www.asmfc.org/uploads/file/riverHerringBenchmarkStockAssessmentVolumeIR_May2012.pdf.]
}

zen and transported to the Annisquam River Marine Fisheries station in Gloucester, Massachusetts. After thawing overnight, TL in millimeters, weight in grams, and sex were recorded for each fish. Sagittal otoliths, scales, opercula, and vertebrae were removed and stored for processing.

Otoliths were rinsed in water and stored dry in microcentrifuge vials. Whole otoliths were placed in a black dish filled with mineral oil and viewed with reflected light through a dissecting microscope at 30-40× magnification for age determination. Left and right otoliths were examined side by side to aid in discerning between annuli and checks. The distal surface of the otoliths provided the clearest view of the annuli.

Scales were stored dry in envelopes before being cleaned in an ultrasonic bath with a 5\% pancreatin solution (Whaley, 1991). From 3 to 5 clean, nonregenerated scales were dried with a paper towel and placed between 2 glass slides. Scales were viewed with transmitted light at 5-10 $\times$ on a digital computer imaging system that included Image-Pro Plus ${ }^{3}$ image analysis software, vers. 6.2 (Media Cybernetics, Inc., Rockville, MD). All scales on a slide were examined to discern annuli from checks, but the scale with clearest annuli was used for age determination.

Opercula were stored frozen before they were boiled for 2-3 min. A small brush was used to clean excess flesh from opercula after they were boiled. The opercula were then rinsed in clean water and air dried for at least 24 hours. Dry opercula were held up to a fluorescent light source, and annuli were enumerated without magnification. Opercula were viewed as pairs to help discern between annuli and checks.

Vertebrae numbers 4-10 were separated with a scalpel. Excess flesh was removed with a scalpel before the vertebrae were soaked for 24-48 hours in a solution of $3 \%$ hydrogen peroxide. After the soaking of the vertebrae, a small brush was used to remove any remaining flesh, and the vertebrae were allowed to air dry for at least 24 hours. Whole vertebrae were viewed under reflected light at 20-30x with a digital computer imaging system with Image-Pro Plus software. All vertebrae from each fish were examined to discern between annuli and checks. The vertebra with clearest annuli was selected for age determination.

Annuli in the otoliths, opercula, and vertebrae were defined as the distal edge of each hyaline zone. We used Cating's (1953) definition of annuli on scales, although we did so with disregard for their position in relation to the location of the transverse grooves because the number of transverse grooves within each annulus as outlined by Cating (1953) was discredited by Duffy et al. (2011). Because all fish in this study

\footnotetext{
${ }^{3}$ Mention of trade names or commercial companies is for identification purposes only and does not imply endorsement by the National Marine Fisheries Service, NOAA.
} 
were captured during the time of presumed annulus formation, the edge of each structure was counted as the final annulus.

Only fish for which all 4 structures were deemed readable were included in this study. Each structure was read independently by 2 readers with no knowledge of fish size, sex, or ages assigned to other structures. Readers used scales, otoliths, opercula, and vertebrae from fish not included in the study to familiarize themselves thoroughly with each type of structure before beginning the final reading. Precision of readings was measured with percent agreement and coefficient of variation (CV) (Chang, 1982) 1) between results for one reader and results for the other reader for each structure, 2) among results for reader 2 for a randomly assigned subsample of 100 fish, and 3) between results for otoliths and results for each of the other 3 structures for each reader. Coefficients of variations were calculated with the equation as shown in Campana (2001):

$$
C V_{j}=100 \% \times \frac{\sqrt{\sum_{i=1}^{R} \frac{\left(X_{i j}-X_{j}\right)^{2}}{R-1}}}{X_{j}} .
$$

This equation gives the $C V$ for the $j^{\text {th }}$ fish, where $X_{i j}=$ the $i$ th age estimate of the $j^{\text {th }}$ fish;

$X_{j}=$ the average age estimate of the $j^{\text {th }}$ fish; and

$R=$ the number of times that fish was aged.

Coefficients of variations listed in this article were averaged across all fish aged. Wilcoxon rank sum tests were used to determine whether differences in age readings existed between otoliths and the other structures. Significance was not tested for fish of ages 3 and 11 because of insufficient sample sizes.

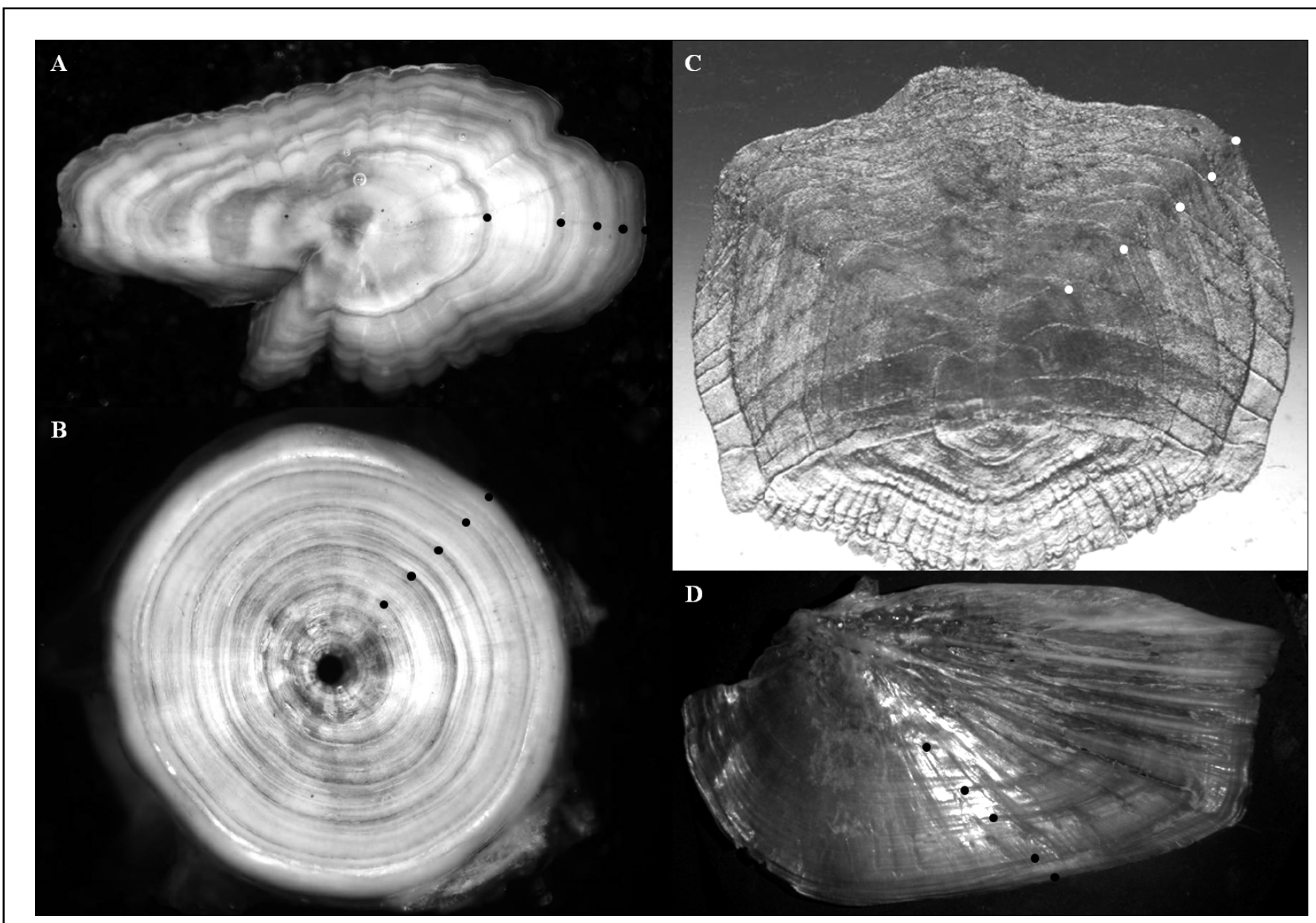

Figure 1

Images of an (A) otolith, (B) vertebra, (C) scale, and (D) operculum from a 5-year-old male American shad (Alosa sapidissima) that was captured on 31 May 2010 in the Merrimack River in Lawrence, Massachusetts. The dots on each image indicate locations of presumed annuli. This fish was captured during the spawning season, which is also the period of annulus deposition; therefore, the edge is counted as the fifth annulus. 

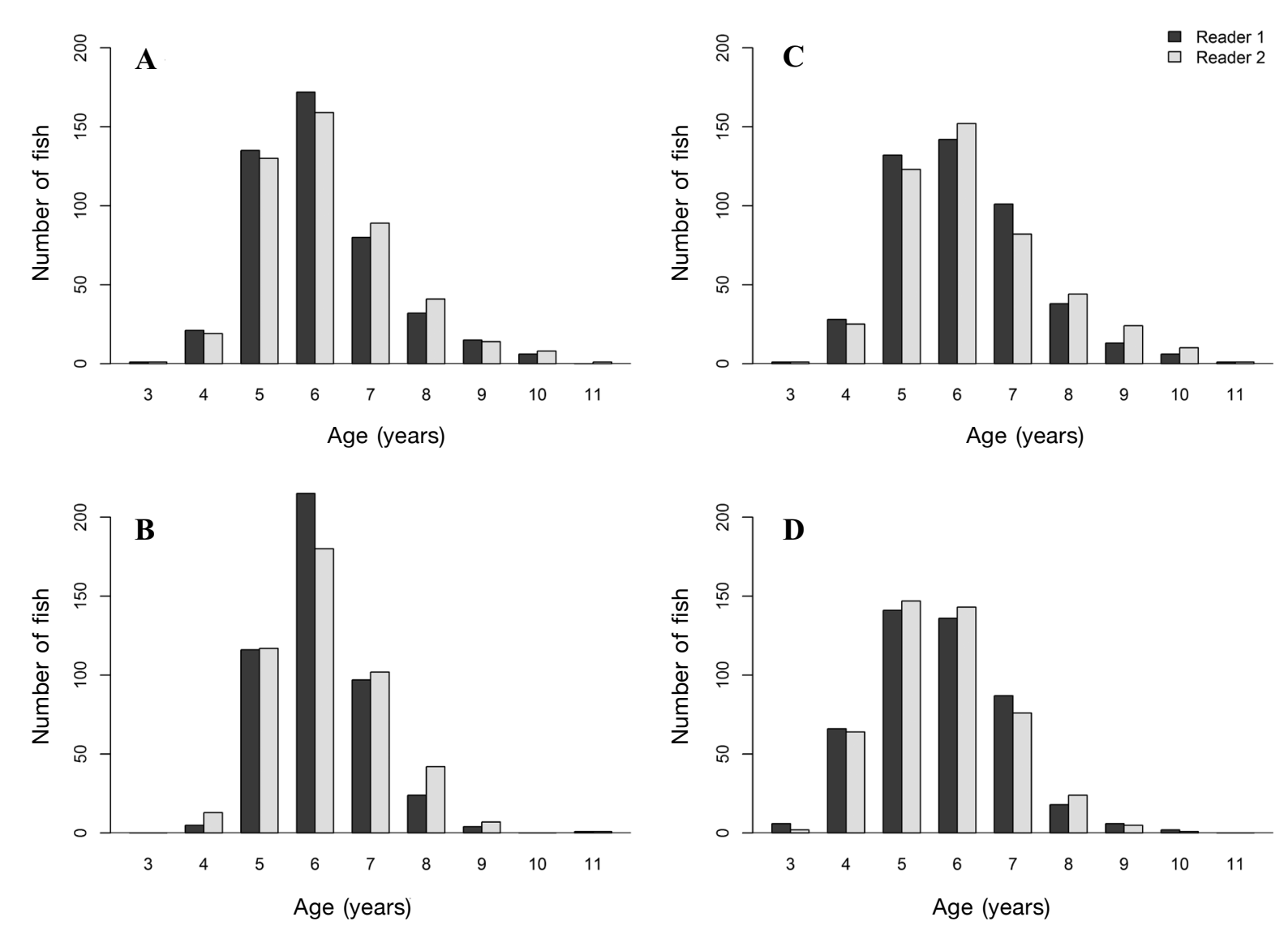

Figure 2

The age structure of the 462 American shad (Alosa sapidissima) collected during May-June in 2008-2010 from the Merrimack River in Lawrence, MA, from annuli in (A) otoliths, (B) scales, (C) vertebrae, and (D) opercula. Annuli were counted by each of 2 readers.

\section{Results}

For this study, 545 American shad were collected. Only 462 fish (283 males, 179 females) were deemed readable for all 4 structures and, therefore, these fish were included in our analyses. Fish with TLs from 401 to $639 \mathrm{~mm}$ (average $=502 \mathrm{~mm}$ ) were represented. Average TL was longer for females than for males (518 versus $477 \mathrm{~mm}$ TL).

All 4 structures that were examined contained annual marks (Fig. 1), but otoliths and vertebrae showed the most defined marks. American shad in this study ranged in age from 3 to 11 years. The majority of fish were age 5 and 6 . No fish were assigned an age of 11 years with the use of opercula or 3 years with scales. Both readers found age- 6 fish at a larger percentage on the basis of scale ages than they did with any other structure (Fig. 2).

Analysis of between-reader and within-reader results for each structure indicated that the most precise age readings came from otoliths: precision was measured between readers with agreement of $76.2 \%$ and a $\mathrm{CV}$ of $2.99 \%$ and among results from a single reader with agreement of $74 \%$ and a $\mathrm{CV}$ of $2.93 \%$. The next most precise age estimates were determined from scales, with agreement of $66.9 \%$ and a CV of $4.28 \%$ between readers and agreement of $65 \%$ and a $\mathrm{CV}$ of $5.1 \%$ within results for a reader. Aging with vertebrae resulted in the third-most precise readings, followed by age analysis with opercula (Table 1). Within-reader comparisons were made between otolith ages and ages determined from the other structures. Vertebral ages matched the otolith ages most closely for reader 1 (55.6\%). Vertebra and scale ages both agreed $53.2 \%$ of the time with otoliths for reader 2 . The $\mathrm{CV}$ for both readers was better between otoliths and vertebrae $(5.95 \%$ and $6.39 \%)$ than between otoliths and scales (6.87\% and 6.63\%). Agreement between opercula and otoliths was the worst for both readers (Table 1 ).

In comparisons of results between readers and within reader 2 , at least $93 \%$ of all age disagreements were within 1 year. For both readers, agreement between ver- 


\section{Table 1}

The precision of age estimates obtained from otoliths, scales, vertebrae, and opercula of American shad (Alosa sapidissima) was tested between readers, within results for a single reader for a subsample of 100 fish, and between structures for each reader. All samples were collected in May and June during 2008-10 from the Merrimack River in Lawrence, Massachusetts. The percent agreement and coefficient of variation $(\mathrm{CV})$ are presented for each comparison.

\begin{tabular}{clcc}
\hline & & $\begin{array}{c}\text { Agreement } \\
(\%)\end{array}$ & $\begin{array}{c}\text { CV } \\
(\%)\end{array}$ \\
\hline \multirow{2}{*}{$\begin{array}{clcc}\text { Between } \\
\text { readers }\end{array}$} & Otolith & 76.2 & 2.99 \\
& Vertebra & 66.9 & 4.28 \\
& Operculum & 63.4 & 4.59 \\
& Otolith & 49.8 & 7.07 \\
Within & Scale & 74.0 & 2.93 \\
reader 2 & Vertebra & 65.0 & 5.10 \\
& Operculum & 56.0 & 5.96 \\
& Otolith vs. scale & 49.0 & 7.32 \\
Reader 1 & Otolith vs. vertebra & 50.6 & 6.87 \\
& Otolith vs. operculum & 54.6 & 5.95 \\
& Otolith vs. scale & 53.2 & 9.80 \\
Reader 2 & Otolith vs. vertebra & 53.2 & 6.63 \\
& Otolith vs. operculum & 34.2 & 9.52 \\
& & & \\
\hline
\end{tabular}

tebral ages and otolith ages was within 1 year $(93.9 \%$ and $92 \%$ ) and 2 years $(99.4 \%, 99.1 \%)$, results that are better than the agreement between scale ages and otolith ages (1 year: $90.9 \%$ and $89.4 \%$; 2 years: $89.3 \%$ and $89.3 \%$ ). More than $99 \%$ of all age disagreements were within 3 years (Table 2).

Wilcoxon rank sum tests between readings from otoliths and those from other structures showed that both readers significantly overestimated the ages of age- 4 and age-5 fish when they used scales and vertebrae. Both readers also underestimated the ages of fish age 6 and older with the use of opercula, as well as ages of fish age 7 and older with the use of scales (Table 3; Fig. 3). Although significance was not tested for age-3 or age-11 fish, because of a sample size of 1 for each age, the limited data for these 2 fish indicate that the trends outlined previously continue into these ages.

\section{Discussion}

On the basis of the presence of strong annular marks on otoliths as well as the lowest $\mathrm{CV}$ and the highest percent agreement between readers and within readers for readings from otoliths in this study, the otolith was deemed the best structure for determining the age of American shad. Furthermore, using fish marked with oxytetracycline as did Hendricks et al. (1991), Duffy et al. (2012) were able to validate the accuracy of aging American shad with the use of otoliths. Additionally, otoliths are moderately easy to remove and require less preparation for aging than any of the other structures examined.

The vertebra was the second-most preferred structure for aging American shad. When compared with otolith ages, vertebral ages were less biased than scale or operculum ages. In a study similar to ours, Yilmaz and Polat (2002) compared the precision of age estimates from otoliths, vertebrae, opercula, subopercula, and scales from pontic shad and found that the most precise aging was performed with vertebrae. However, Višnjić-Jeftić et al. (2009) found that the precision of aging the pontic shad was dependent more on the experience of the reader than on the structure being aged. Readers in our study had minimal prior experience in aging vertebrae. Therefore, with practice for readers, vertebral ages for American shad could approach the level of precision seen with otolith ages. However, the work to remove and process vertebrae was more labor-intensive than the effort required for otoliths, and there- 


\section{Table 3}

American shad (Alosa sapidissima), collected in May and June during 2008-10 from the Merrimack River in Lawrence, Massachusetts, were aged by 2 readers. Each reader used otoliths, scales, vertebrae, and opercula to determine the age of each fish. The average age assigned to each structure for each otolith age is shown. An asterisk $(*)$ denotes significant differences $(P<0.05)$ from the otolith ages determined with Wilcoxon rank sum tests. Significance was not tested for ages 3 and 11 because of insufficient sample size $(n)$.

\begin{tabular}{crrrr}
\hline Otolith age & Vertebra & Scale & Operculum & $n$ \\
\hline Reader 1 & & & & \\
3 & 3.00 & 4.00 & 3.00 & 1 \\
4 & $* 4.48$ & $* 4.95$ & 4.10 & 21 \\
5 & $* 5.29$ & $* 5.53$ & 4.98 & 135 \\
6 & 5.99 & 6.09 & $* 5.73$ & 172 \\
7 & 6.88 & $* 6.63$ & $* 6.30$ & 80 \\
8 & 7.84 & $* 7.00$ & $* 7.00$ & 32 \\
9 & $* 8.40$ & $* 7.07$ & $* 7.20$ & 15 \\
10 & 9.50 & $* 7.83$ & $* 7.83$ & 6 \\
Reader 2 & & & & \\
3 & 3.00 & 5.00 & 3.00 & 1 \\
4 & $* 4.68$ & $* 4.74$ & 4.26 & 19 \\
5 & $* 5.25$ & $* 5.42$ & 4.93 & 130 \\
6 & 6.03 & 6.09 & $* 5.65$ & 159 \\
7 & 7.00 & $* 6.72$ & $* 6.22$ & 89 \\
8 & 7.71 & $* 7.29$ & $* 6.85$ & 41 \\
9 & 8.86 & $* 7.36$ & $* 7.71$ & 14 \\
10 & 9.63 & $* 8.13$ & $* 7.63$ & 8 \\
11 & 10.00 & 8.00 & 7.00 & 1 \\
& & & & \\
\hline
\end{tabular}

fore the vertebra is a less ideal structure for production aging.

In this study, age estimates obtained from scales of American shad were not as precise as those produced from otoliths and were more biased toward underaging older ( $\geq 7$ years) fish than were age estimates obtained from vertebrae. For these reasons, the scale is not viewed as a preferred aging structure. The use of scales for age determination had the advantage of being the only nonlethal method tested in this study. However, we found that many scales were regenerated and, therefore, not suitable for age determination. Although scales can provide data regarding repeat spawning behavior (Cating, 1953), information that is used in the management of the American shad $\left(\mathrm{ASMFC}^{2}\right.$ ), the spawning marks left by reabsorption of the scale margin during a freshwater spawning run (Cating, 1953) can hinder the use of scales for accurate age determination. If enough of the scale is reabsorbed, annuli laid down in previous years can be very difficult to interpret.

The results of our study agree with the findings of McBride et al. (2005) that indicate that scales produce biased ages, where readers tend to over-age young $(\leq 5$

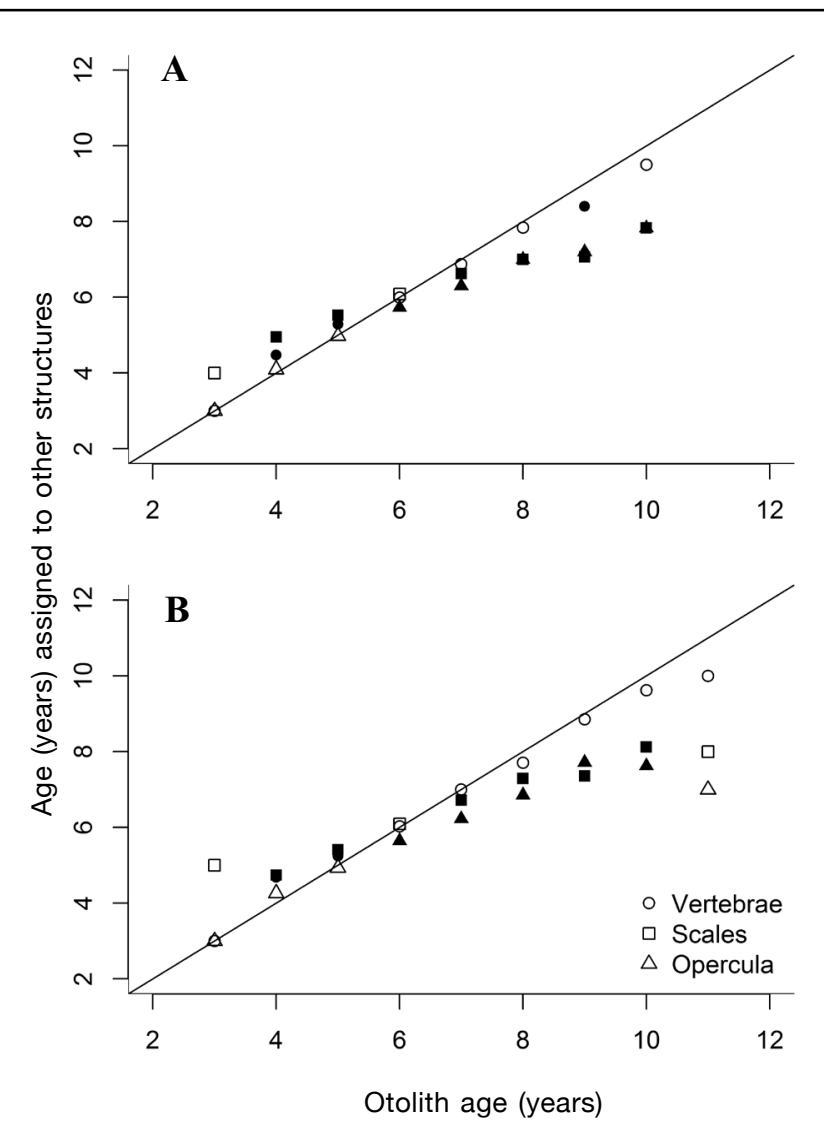

Figure 3

Ages from otoliths of American shad (Alosa sapidissi$\mathrm{ma}$ ) collected in May and June during 2008-2010 from the Merrimack River in Lawrence, Massachusetts, compared with the average ages assigned through the use of vertebrae, scales, and opercula by $(\mathbf{A})$ reader 1 and (B) reader 2. The diagonal line represents agreement with otoliths. Filled symbols represent ages that are significantly different $(P<0.05)$ from ages from otoliths; empty symbols are not. Significance was tested with Wilcoxon rank sum tests for ages 4-10. Significance was not tested for ages 3 or 11 because of a sample size of 1 for each age.

years) fish and under-age older fish. Furthermore, Upton et al. (2012) showed a 50\% error in scale ages of American shad of known age. This trend of otoliths providing better precision and a larger range of ages than those provided by scales has been shown in several other species as well (Barnes and Power, 1984; Welch et al., 1993; Secor et al., 1995; Sipe and Chittenden, 2001; Zymonas and McMahon, 2009).

Opercula resulted in the least reliable readings in this study of aging structures for American shad. Opercula were difficult to read, required more processing than scales or otoliths, and provided estimates of the lowest precision compared with results from the other structures examined. Contrary to the findings of 
Yilmaz and Polat (2002) with pontic shad, we did not find annuli easy to distinguish in opercula of the American shad, especially in older ( $\geq 6$ years) fish. Furthermore, our ages determined from opercula were biased compared with ages derived from otoliths, leading to fish of age 5 and older being under-aged.

The results of this study support the use of otoliths for age determination of American shad. Ages estimated from otoliths were more precise (between and within readers) than ages derived from any of the other structures examined. Campana (2001) suggested a CV of $5 \%$ or less is ideal for a species of moderate longevity. In this study, only ages from otoliths achieved a CV of less than $5 \%$ between and within readers. Ages estimated from scales and vertebrae were higher in young ( $\leq 5$ years) fish than ages determined from otoliths. Furthermore, ages estimated from scales and opercula were lower than ages from otoliths in older ( $\leq 7$ years) fish. If possible, a reference collection of otoliths should be compiled for each region for which age estimates would be useful. Such a collection could provide a valuable tool for training inexperienced readers of annuli, as well as would prevent a long-term drift for age estimates determined by experienced personnel (Campana, 2001).

\section{Acknowledgments}

We would like to thank the employees of the Massachusetts Division of Fisheries and Wildlife that helped sample American shad at the Essex dam in Lawrence. We also thank S. Turner for her help in processing samples. We also appreciate the thorough comments provided by M. Armstrong and G. Nelson on revisions at the manuscript stage. Funding for this project was provided, in part, through the Wildlife and Sport Fish Restoration Program of the U.S. Fish and Wildlife Service (Massachusetts Sport Fish Restoration Grant F-68-R).

\section{Literature cited}

Barnes, M. A., and G. Power.

1984. A comparison of otolith and scale ages for western Labrador lake whitefish, Coregonus clupeaformis. Environ. Biol. Fish. 10:297-299.

Beamish, R. J., and H. H. Harvey.

1969. Age determination in the white sucker. J. Fish. Res. Board Can. 26:633-638. doi: 10.1139/f69-057.

Beamish, R. J., and G. A. McFarlane.

1983. The forgotten requirement for age validation in fisheries biology. Trans. Am. Fish. Soc. 112:735743. doi: 10.1577/1548-8659(1983)112<735:TFRFAV> 2.0.CO;2.

Boxrucker, J.

1986. A comparison of the otolith and scale methods for aging white crappies in Oklahoma. N. Am. J. Fish. Man- age. $6: 122-125$. doi: 10.1577/1548-8659(1986)6<122:AC OTOA $>2.0 . C O ; 2$.

Campana, S. E.

2001. Accuracy, precision and quality control in age determination, including a review of the use and abuse of age validation methods. J. Fish Biol. 59:197-242. doi: 10.1111/j.1095-8649.2001.tb00127.x.

Cating, J. P.

1953. Determining age of Atlantic shad from their scales. Fish. Bull. 54:187-199.

Chang, W. Y. B.

1982. A statistical method for evaluating the reproducibility of age determination. Can. J. Fish. Aquat. Sci. 39:1208-1210. doi: 10.1139/f82-158.

Collette, B. B., and G. Klein-MacPhee (eds).

2002. Bigelow and Schroeder's fishes of the Gulf of Maine, $3^{\text {rd }}$ ed., 748 p. Smithsonian Institution Press, Washington, D.C.

Duffy, W. J., R. S. McBride, S. X. Cadrin, and K. Oliveira.

2011. Is Cating's method of transverse groove counts to annuli applicable for all stocks of American shad? Trans. Am. Fish. Soc. 140:1023-1034. doi: 10.1080/00028487.2011.603985.

Duffy, W. J., R. S. McBride, M. L. Hendricks, K. Oliveira.

2012. Otolith age validation and growth estimation from oxytetracycline-marked and recaptured American shad. Trans. Am. Fish. Soc. 141:1664-1671. doi: 10.1080/00028487.2012.720631

Hassleman, D. J., D. Ricrad, and P. Bentzen.

2013. Genetic diversity and differentiation in a wide ranging anadromous fish, American shad (Alosa sapidissima), is correlated with latitude. Mol. Ecol. 22:15581573. doi: $10.1111 / \mathrm{mec} .12197$.

Hendricks, M. L., T. R. Bender Jr., and V. A. Mudrak.

1991. Multiple marking of American shad otoliths with tetracycline antibiotics. N. Am. J. Fish. Manage. 11:212-219.

Latour, R. J., E. J. Hilton, P. D. Lynch, T. D. Tuckey, B. E. Wat-

kins, and J. E. Olney.

2012. Evaluating the current status of American shad stocks in three Virginia rivers. Mar. Coast. Fish. 4:302-311 doi: 10.1080/19425120.2012.675978.

Leggett, W. C., and J. E. Carscadden.

1978. Latitudinal variation in reproductive characteristics of American shad (Alosa sapidissima): evidence for populations specific life history strategies in fish. J. Fish. Res. Board Can. 35:1469-1478. doi: 10.1139/ f78-230.

McBride, R. S., M. L. Hendricks, and J. E. Olney.

2005. Testing the validity of Cating's (1953) method for age determination of American shad using scales. Fisheries 30:10-18. doi: 10.1577/1548-8446(2005)30[10:TT$\mathrm{VOCM}] 2.0 . \mathrm{CO} ; 2$.

Raabe, J. K., and J. E. Hightower.

2014. American shad migratory behavior, weight loss, survival, and abundance in a North Carolina river following dam removals. Trans. Am. Fish. Soc. 143:673688. doi: 10.1080/00028487.2014.882410.

Robillard, E., C. S. Reiss, and C. M. Jones.

2009. Age-validation and growth of Bluefish (Pomatomus saltatrix) along the East Coast of the United States. Fish. Res. 95:65-75. doi: 10.1016/j. fishres.2008.07.012. 
Ross, M. R.

1991. Recreational fisheries of coastal New England, 279

p. Univ. Mass. Press, Amherst, MA.

Scott, W. B., and A. H. Leim.

1966. Fishes of the Atlantic coast of Canada, 485

p. Fish. Res. Board Canada, Ottawa.

Scott, W. B. and M. G. Scott.

1988. Atlantic fishes of Canada. Can. Bull. Fish. Aquat. Sci. 219,731 p.

Secor, D. H., T. M. Trice, and H. T. Hornick.

1995. Validation of otolith-based ageing and a comparison of otolith and scale-based ageing in mark-recaptured Chesapeake Bay striped bass, Morone saxatilis. Fish. Bull. 93:186-190.

Sipe, A. M., and M. E. Chittenden Jr.

2001. A comparison of calcified structures for aging summer flounder, Paralichthys dentatus. Fish. Bull. 99:628-640.

Stolarski, J. T., and T. M. Sutton.

2013. Precision analysis of three aging structures for amphidromous Dolly Varden from Alaskan Arctic rivers. N. Am. J. Fish. Manage. 33:732-740. doi: 10.1080/02755947.2013.806379.

Sylvester, R. M., and C. R. Berry Jr.

2006. Comparison of white sucker age estimates from scales, pectoral fin rays, and otoliths. N. Am. J. Fish. Manage. 26:24-31. doi: 10.1577/M04-147.1.

Thompson, K. R., and D. W. Beckman.

1995. Validation of age estimates from white sucker otoliths. Trans. Am. Fish. Soc. 124:637-639. doi: 10.1577/1548-8659(1995)124<0637:VOAEFW>2.3. $\mathrm{CO} ; 2$.
Upton, S. A., B. D. Walther, S. R. Thorrold, and J. E. Olney. 2012. Use of a natural isotopic signature in otoliths to evaluate scale-based age determination for American shad. Mar. Coast. Fish. 4:346-357. doi: 10.1080/19425120.2012.675973.

Višnjić-Jeftić, Ž., M. Lenhardt, I. Navodaru, A. Hegediš, Z. Gačić, and M. Nikčević.

2009. Reproducibility of age determination by scale and vertebra in Pontic shad (Alosa pontica Eichwald, 1838), from the Danube. Arch. Biol. Sci., Belgrade 61:337-342.

Walburg, C. H., and P. R. Nichols.

1967. Biology and management of the American shad and status of the fisheries, Atlantic coast of the United States, 1960. U.S. Fish Wildl. Serv. Spec. Sci. Rep. SSRF-550, $105 \mathrm{p}$.

Welch, T. J., M. J. van den Avyle, R. K. Betsill, and E. M. Driebe.

1993. Precision and relative accuracy of striped bass age estimates from otoliths, scales, and anal fin rays and spines. N. Am. J. Fish. Manage. 13:616-620.

Whaley, R. A.

1991. An improved technique for cleaning fish scales. N. Am. J. Fish. Manage. 11:234-236. doi: 10.1577/15488675(1991)011<0234:AITFCF>2.3.CO;2.

Yilmaz, S., and N. Polat.

2002. Age determination of shad (Alosa pontica Eichwald, 1838) inhabiting the Black Sea. Turk. J. Zool. 26:393-398.

Zymonas, N. D., and T. E. McMahon.

2009. Comparison of pelvic fin rays, scales and otoliths for estimating age and growth of bull trout, Salvelinus confluentus. Fish. Manage. Ecol. 16:155-164 